\title{
UV Irradiation and Ozone Treatment of א-Carrageenan: Kinetics and Products Characteristics
}

\author{
Aji Prasetyaningrum ${ }^{1, *}$, W. Widayat ${ }^{1}$, Bakti Jos $^{1}$, Yudhy Dharmawan ${ }^{2}$, R. Ratnawati ${ }^{1}$ \\ ${ }^{1}$ Department of Chemical Engineering, Diponegoro University, Jl. Prof. Soedarto S.H., Tembalang, \\ Semarang 50239, Indonesia. \\ ${ }_{2}^{2}$ Faculty of Public Health, Diponegoro University, Jl. Prof. Soedarto S.H., Tembalang, Semarang \\ 50269, Indonesia.
}

\begin{abstract}
Received: $10^{\text {th }}$ January 2020; Revised: $9^{\text {th }}$ March 2020; Accepted: $13^{\text {th }}$ March 2020; Available online: $30^{\text {th }}$ July 2020; Published regularly: August 2020
\end{abstract}

\begin{abstract}
The low molecular weight (LMW) of sulfated polysaccharides including $\kappa$-carrageenan, is shows a wide spectrum of biological activities. This research investigates the influence of UV irradiation, ozone $\left(\mathrm{O}_{3}\right)$, and the combination of $\mathrm{O}_{3} / \mathrm{UV}$ methods on the depolymerization of $\kappa$-carrageenan. The depolymerization kinetics of $\kappa$-carrageenan using the Advanced Oxidation Process $\left(\mathrm{UV}^{-\mathrm{O}_{3}}\right)$ was also studied. Furthermore, the intrinsic viscosity method was used to determine the average molecular weight of the research sample, and a mathematical model was developed to predict the kinetic rate constant, as a function of ozone dosage and UV irradiation intensity. Therefore, the physicochemical and morphological properties of the degraded $\kappa$-carrageenan were analyzed by FT-IR, SEM, and XRD. The intrinsic viscosity $\kappa$-carrageenan decreases with increasing UV light intensity and ozone concentration. The combination of $\mathrm{UV} / \mathrm{O}_{3}$ treatment appeared to be more effective than the individual approaches, as the highest kinetic rate constant for depolymerization was $1.924 \times 10^{-4} \mathrm{~min}^{-1}$, using 125 $\mathrm{mg} / \mathrm{L}$ ozone concentration and $40 \mathrm{~mW} / \mathrm{cm}^{2}$ of UV lamp intensity. This research also evaluated the relationship between various experimental conditions, including UV lamp power dissipation and ozone concentration on the reaction kinetics model, and the results suggest that lower effect is contributed by UV irradiation intensity. In addition, FT-IR spectra showed the absence of any significant change in the functional properties of $\kappa$-carrageenan treated with $\mathrm{UV}$ and $\mathrm{O}_{3}$ processes, although the morphological properties of the LMW $\kappa$-carrageenan were rougher and more porous than the native $\kappa$ carrageenan. Copyright (C) 2020 BCREC Group. All rights reserved
\end{abstract}

Keywords: к-carrageenan; UV irradiation; ozone; depolymerization

How to Cite: Prasetyaningrum, A., Widayat, W., Jos, B., Dharmawan, Y., Ratnawati, R. (2020). UV Irradiation and Ozone Treatment of $\kappa$-Carrageenan: Kinetics and Products Characteristics. Bulletin of Chemical Reaction Engineering \& Catalysis, 15(2), 319-330 (doi:10.9767/bcrec.15.2.7047.319-330)

Permalink/DOI: https://doi.org/10.9767/bcrec.15.2.7047.319-330

\section{Introduction}

Carrageenan is a high molecular weight sulfated polygalactose obtained from the marine macroalgae (Rhodophyceae). These are further

* Corresponding Author.

E-mail: aji.prasetyaningrum@che.undip.ac.id

Telp: +62-24-7460058, Fax: +62-24-76480675 classified according to the 3,6 anhydrogalactose present on the 4-linked residue, as well as the number and position of the sulfate group. Generally, three types have been identified, including the iota ( $(-)$, lambda $(\lambda-)$ and kappa $(\kappa)$ carrageenan, which is specifically the most widely cultivated in Indonesian waters. The $\kappa$ carrageenan consists of a common D-galactose backbone, characterized by alternating $\beta(1,3)$-D- 
galactose-4-sulfate and $\alpha(1,4)-3,6$ anhydro-Dgalactose, and is widely used in the food industry. This is due to the ability to enhance rheological properties in food products, therefore, serving as stabilizers, emulsifiers, gelling agents [1]. In addition, the average molecular weight of $\kappa$-carrageenan is above $100 \mathrm{kDa}$, with an ester sulfate content of $15-40 \%$, and the chemical structure is depicted in Figure 1.

In recent years, there has been a rising interest in the development of marine resources due to the excellent biological activity and functional physical properties [2]. Furthermore, low molecular weight (LMW) carrageenans have attracted much attention in pharmacology and biomedical function, based on the possible anti-tumor [3], anti-oxidant [4], anti-viral [5-6], immunomodulatory [3,7] and anti-coagulant [7] characteristics. The production of LMW has been achieved through thermal degradation [8], acid hydrolysis [3-5], enzymatic hydrolysis $[4,9,10]$, microwave [11], sonication [12-13], irradiation [14], and oxidation with hydrogen peroxide [15]. Meanwhile, results of previous studies indicate acid hydrolysis as a common and fast method for producing oligosaccharides, although the chemicals added in the depolymerization process have been affiliated with the potential increase in environmental pollution. Conversely, the use of the enzymatic method is not preferable, due to the relatively expensive and complex process.

There are several studies showing the capacity for Advanced Oxidation Processes (AOPs) to reduce polysaccharide viscosity and molecular weight [16-21]. This technology has recently been proven to be a more effective and economical approach to the production of oligomers. In addition, ozone is a strong oxidizing agent, recognized by the United States Food and Drug Administration (FDA) for the general application in industrial food, although the use is limited in ozonation as a result of low mass transfer rate.

The combination of the AOP $\left(\mathrm{UV} / \mathrm{O}_{3}\right)$ technique for the depolymerization of

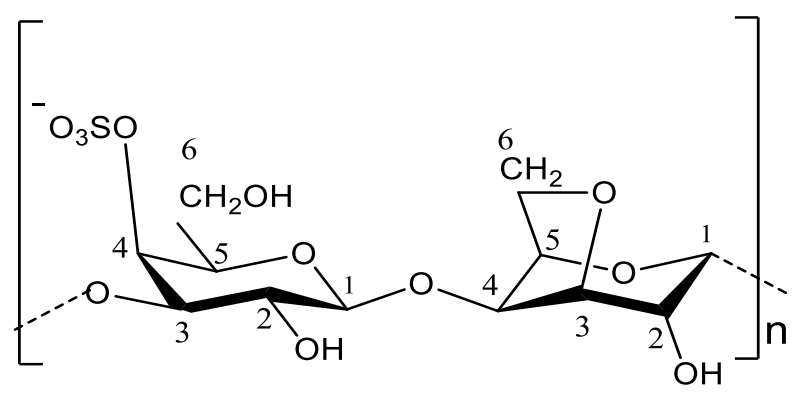

Figure 1. The structure of $\kappa$-carrageenan. polysaccharides has been used by several research [16-19]. These technologies are recognized to be more effective and economical in the production of oligomers, based on the following benefits: absence of chemicals and degradation-resistant fraction residues, as well as the reaction safety and conduction at room temperature [16]. Prajapat et al. [16] investigated the reduction effect of combining ultraviolet and ozone on the molecular weight of guar gums. Yue et al. [17] described the depolymerization of chitosan, which occurred by ultraviolet radiation-induced technique accelerated by ozone treatment. Guirguis et al. [18] reported on the potential for combining $\mathrm{UV} / \mathrm{O}_{3}$ to improve the bacterial activity of chitosan in the pharmaceutical field, while Wang et al. [19] evaluated the content reducing effect on clofibric acid.

Various studies on the kinetics of macromolecular degradation using a combination of $\mathrm{UV} / \mathrm{O}_{3}$ processes have been investigated previously. Chen et al. [20] reported on the kinetics and pathways of $\mathrm{N}$ Nitrosopyrrolidine degradation using $\mathrm{UV} / \mathrm{O}_{3}$, while Dai et al. [21] explored the degradation effect of ozonation on phenoxy acetic acid (PPA) at different initial $\mathrm{pH}$, as well as PPA and ozone concentration. The literature review shows the total absence of studies concerning the efficacy of combining $\mathrm{UV} / \mathrm{O}_{3}$ in attempts to reduce $\kappa$-carrageenan molecular weight. The novelty of this research, therefore, is to develop a relationship between the experimental conditions, including UV lamp power dissipation and ozone concentration on the $\kappa$ carrageenan depolymerization reaction kinetics model. Furthermore, understanding the physicochemical properties of LMW varieties is essential for better application, hence the characterization of chemical structural identity and morphological properties, alongside the native form. This assessment required the use of Fourier transform infrared (FT-IR), X-ray diffraction (XRD), and Scanning Electron Microscope (SEM).

\section{Materials and Methods}

\subsection{Materials}

The semi-refined $\kappa$-carrageenan raw material was extracted from Kappaphycus alvarezii, possessing an average molecular weight of 460 $\mathrm{kDa}$. This was then purified by diluting the powder in distilled water at $70{ }^{\circ} \mathrm{C}$, followed by precipitation through the dropwise addition of isopropyl alcohol (E. Merck, Catalog No. 
818766) with vigorous stirring. Therefore, the precipitate was filtered and dried at $60{ }^{\circ} \mathrm{C}$ in a forced-air oven, which was followed by analysis by dissolving at $1 \% \mathrm{w} / \mathrm{v}$ concentration. In addition, all chemicals in this investigation were used without any pretreatment.

\subsection{Experimental Setup and Procedure}

UV irradiation was performed using a UV bench irradiator that consists of three UV lamps (253.7 nm, T5 UV-C, 8 W, Philips). A 500 $\mathrm{mL}$ sample was placed in the $12 \mathrm{~cm}$ inner diameter glass reactor and directly illuminated from the top direction, as the sample was slowly stirred at ambient temperature. This study used various UV light radiation energy (8, 16 and $24 \mathrm{Watt})$, and the illuminated area measured $20 \mathrm{~cm} \times 30 \mathrm{~cm}$. Therefore, the energy per unit area was estimated at 13.33, 26.67 and $40 \mathrm{~mW} / \mathrm{cm}^{2}$.

For the $\mathrm{UV} / \mathrm{O}_{3}$ experiment, ozone gas was produced through the passage of air to the ozone generator (dielectric barrier discharge) at a high potential difference $( \pm 30 \mathrm{kV})$. The generated concentration varied at 45,80 and 125 $\mathrm{mg} / \mathrm{L}$, which was then inserted from the bottom of the reactor with a gas sparger. Moreover, the initial $\mathrm{pH}$ of all experiments was adjusted to 8 . This measurement required the use of $\mathrm{pH}$ meter (HI 98107), and the results were taken at $5,10,15,20,25$ and 30 minutes, respectively. Therefore, $\kappa$-carrageenan treated with ozonation only, UV irradiation only and the $\mathrm{UV} / \mathrm{O}_{3}$ combination were collected, rinsed with distilled water, and filtered with Buchner funnel. After the depolymerization process, the intrinsic viscosity of the LMW product was measured to determine the average molecular weight (M), followed by the analysis of functional and morphological properties using FT-IR, SEM, and XRD. Figure 2 shows the experimental set up for $\mathrm{UV} / \mathrm{O}_{3}$ treatment.

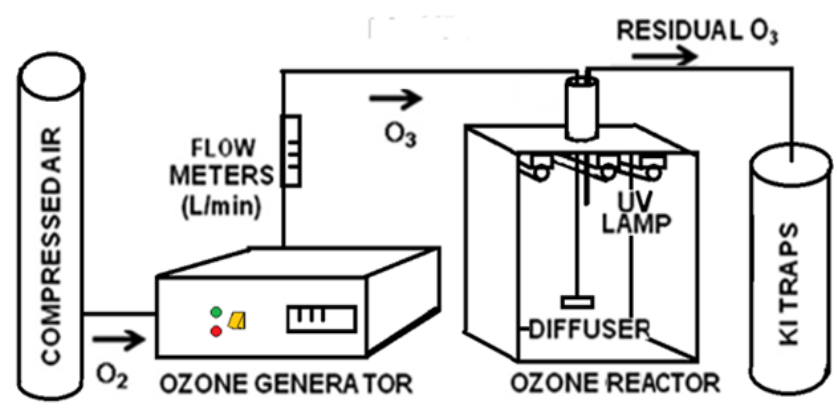

Figure 2. The experimental set up of $\mathrm{UV} / \mathrm{O}_{3}$ treatment.

\subsection{Analysis}

FT-IR spectroscopy was used to determine the functional properties of native and depolymerized $\kappa$-carrageenan, by sieving the samples through a 200 mesh, which is then mixed with $\mathrm{KBr}$ powder (1:100). The infrared spectrometric analysis was conducted using a Perkin Elmer Spectrometer IR 10.6.1 calibrated in the range of 2000-400 $\mathrm{cm}^{-1}$, with a resolution of $4 \mathrm{~cm}^{-1}$. Furthermore, the XRD patterns were measured with an X-ray diffractometer (XRD-7000, Shimadzu, Japan), with a scanning region of $10^{\circ}$ to $80^{\circ}$, a voltage of 30 $\mathrm{kV}, 30 \mathrm{~mA}$, and a scan speed of $5 \% \mathrm{~min}$. The morphological characterization was carried out using a Scanning electron microscope JSM6510-LA JEOL series, Japan, as both samples were sprinkled onto adhesive Aluminium or Carbon tapes, supported on metallic discs, and coated with Aurum. Therefore, the surface images obtained were recorded in different magnifications.

\subsection{Viscosity Measurement}

The intrinsic viscosities of the native $\kappa$ carrageenan and the degraded solutions at 25 ${ }^{\circ} \mathrm{C}$ were measured using the Ubbelohde capillary viscometer (type 531 030c SchottGerate, Germany), and the efflux times measured using a capillary viscometer at a constant temperature of $45.0 \pm 0.1{ }^{\circ} \mathrm{C}$. This value was obtained for both $\kappa$-carrageenan solutions $(t)$ and the solvent $\left(t_{0}\right)$ in duplicate, and the average was then converted using a ratio of $t / t_{0}$, which is equivalent to the solution relative viscosity $\left(\eta_{r}\right)$ (Equation (1)).

$$
\begin{aligned}
& \eta_{r}=\frac{t}{t_{0}} \\
& \eta_{s p}=\eta_{r}-1
\end{aligned}
$$

The intrinsic viscosity $[\eta]$ values can be related to the specific viscosity $\left(\eta_{s p}\right)$ (Equation (2)) and relative viscosity $\left(\eta_{r}\right)$, by the Huggins and Kramer equations [8] as shown in Equation (3):

$$
\frac{\eta_{s p}}{C}=[\eta]+k_{H}[\eta]^{2} C
$$

where $C$ and $k_{H}$ are the concentration of the solution and Huggins constant, respectively. Moreover, the specific viscosity $\left(\eta_{s p}\right)$ and the Huggins constant $\left(k_{H}\right)$ are dimensionless, while intrinsic viscosity $([\eta])$ and concentration $(C)$ have units of $\mathrm{mL} / \mathrm{g}$ and $\mathrm{g} / \mathrm{mL}$, respectively, and 
the value of $k_{H}$ for a $\mathrm{k}$-carrageenan solution is $0.35[8]$.

\section{Results and Discussion}

3.1 Comparison of $\mathrm{UV}, \mathrm{O}_{3}$ and $\mathrm{UV} / \mathrm{O}_{3}$ on the degradation of $\mathrm{\kappa}$-carrageenan

\subsubsection{Effect of UV radiation}

This study was conducted to evaluate the effect of UV radiation treatment on the viscosity of $\kappa$-carrageenan, and all experiments were performed at $29 \pm 1{ }^{\circ} \mathrm{C}$ and $\mathrm{pH}$ 8. Figure 3 shows the effect of UV lamp intensity on intrinsic viscosity of $\kappa$-carrageenan from the initial value was $6.94 \mathrm{~mL} / \mathrm{g}$. The intrinsic viscosity reduced to $3.80,3.51$, and $3.01 \mathrm{~mL} / \mathrm{g}$ during illumination with UV lamp power dissipation of $13.33,26.67$ and $40.00 \mathrm{~mW} / \mathrm{cm}^{2}$, respectively. The degree of reduction in the intrinsic viscosity of $\kappa$-carrageenan increased from $45.22 \%$ to $56.73 \%$ with an increase in the UV lamp energy dissipation.

The use of higher UV lamp power dissipation has been predicted to increase the amount of hydroxyl radicals, which also influences the rupture of polysaccharides chains to yield smaller units. This energy transfer has been affiliated with the induction of polysaccharide molecular chain scission, and hydroxyl radicals have been attributed as the most powerful oxidant $\left(E^{0}=2.80 \mathrm{~V}\right)$ amongst these chemical species. During the irradiation process, the extent of depolymerization is directly proportional to the quantum hydroxyl radical produced.

Prajapat et al. [16] reported on the scission of molecular bonds and the reduced intrinsic

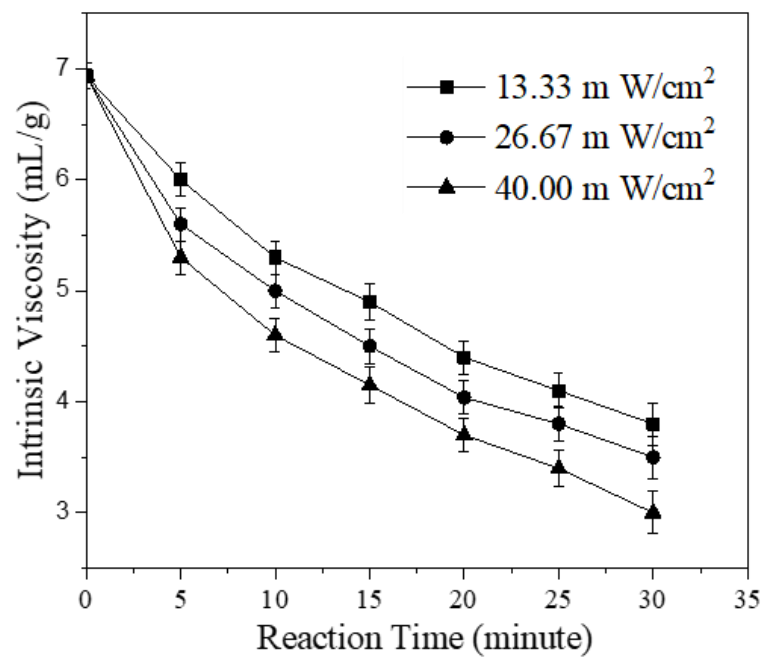

Figure 3. Effect of UV treatment on the viscosity of $\kappa$-carrageenan. viscosity of guar gum solution from $33.4 \%$ to $77.9 \%$, during UV irradiation treatment with an increase in tube dissipation power from $8 \mathrm{~W}$ to $32 \mathrm{~W}$. Pawar et al. [22] reported on a similar tendency for increased polyvinyl pyrrolidone (PVP) solution degradation by UV treatment. Also, the destruction rate of photocatalytic, e.g. poly (alkyl acrylates) under UV/solar exposure was significantly elevated at higher oxidizer concentrations [23]. In addition, the polymer chains are broken down into oligomers, dimers, and monomers, and enhanced polymer photodegradation leads to a reduction and broader distribution of molecular weights. This phenomenon consequently increases the polydispersity of polysaccharides [24].

\subsubsection{Effect of Ozone}

This study was performed in order to investigate the efficacy of the ozonation process in reducing the viscosity of $\kappa$-carrageenan. Figure 4 shows the influence of ozone concentration on the extent of degradation, which was $82.70 \%, 88.46 \%$ and $91.59 \%$, respectively after 30 minutes of treatment with input ozone concentration of 45,80 and $125 \mathrm{mg} / \mathrm{L}$. Prasetyaningrum et al. [25] affiliated the reduction in $\kappa$-carrageenan solution viscosity to ozone treatments, which is closely related to the effectiveness of the depolymerization process. Therefore, the use of ozone alone leads to the production of hydroxyl radicals as shown in Equation (4) and (5).

$$
\begin{aligned}
& \mathrm{O}_{3} \rightarrow \mathrm{O}_{2}+\mathrm{O} \bullet \\
& \mathrm{O} \bullet+\mathrm{H}_{2} \mathrm{O} \rightarrow 2 \cdot \mathrm{OH}
\end{aligned}
$$

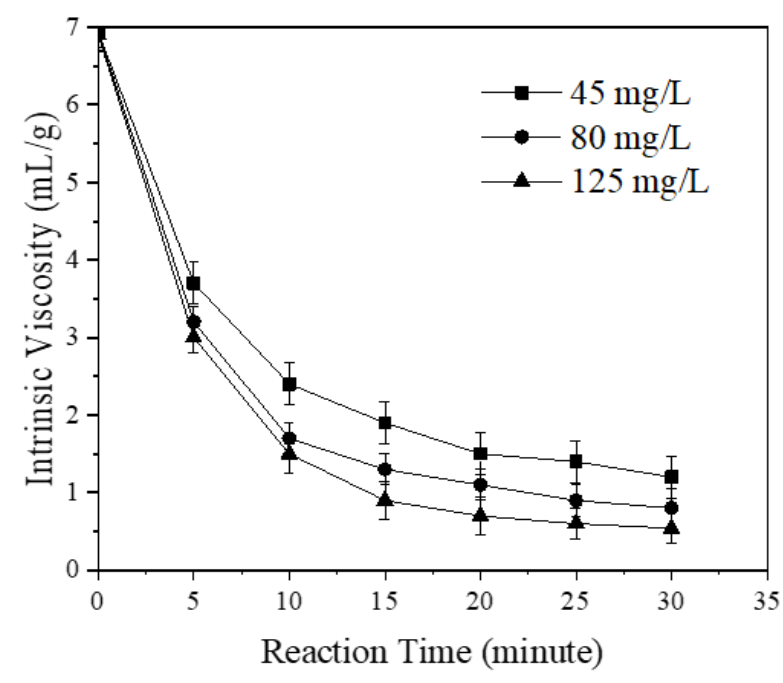

Figure 4. Effect of ozone dosage on the reduction of $\kappa$-carrageenan. 
These radicals possess the capacity to break down the galactose linkages in $\kappa$-carrageenan, which subsequently causes a reduction in intrinsic viscosity. The results obtained showed a similar trend as observed in the ozonation of chitosan, which featured a considerable decline in viscosity to $63 \%$ after $10 \mathrm{~min}$ of treatment [26]. The impact of this treatment on the physico-chemical properties of carbohydrates isolated from A.indicum was reported by Mzoughi et al. [27]. Tiwari et al. [28] assessed the influence on the properties of guar, CMC, and pectin, while Chan et al. [29] observed a decrease in the viscosity of corn, sago, and tapioca. Cataldo et al. [30] reported on changes in gelatin, following a 3 hours ozonation period. However, an increase in the reduced intrinsic viscosity of chitosan from 31.18 to $41.38 \%$ was observed at an elevated ozone flow rate from 35 to $65 \mathrm{mg} / \mathrm{min}$ [17].

\subsubsection{Effect Combining $\mathrm{UV} / \mathrm{O}_{3}$}

The combination of $\mathrm{UV} / \mathrm{O}_{3}$ treatment during $\kappa$-carrageenan depolymerization required an ozone flow rate of $125 \mathrm{mg} / \mathrm{L}$ and a UV irradiation power of $40.00 \mathrm{~mW} / \mathrm{cm}^{2}$. Figure 5 demonstrates the relatively enhanced effectiveness of this technique, over the individual treatment, as the extent of degradation recorded for $\mathrm{UV}, \mathrm{O}_{3}$, and the combination of $\mathrm{UV} / \mathrm{O}_{3}$ were $53.86 \%, 91.59 \%$, and $96.68 \%$, respectively. In addition, the ozone treatment was assumed to provide higher activity than the UV irradiation, indicating a greater tendency for higher radiolysis to increase in the number of hydroxyl radicals

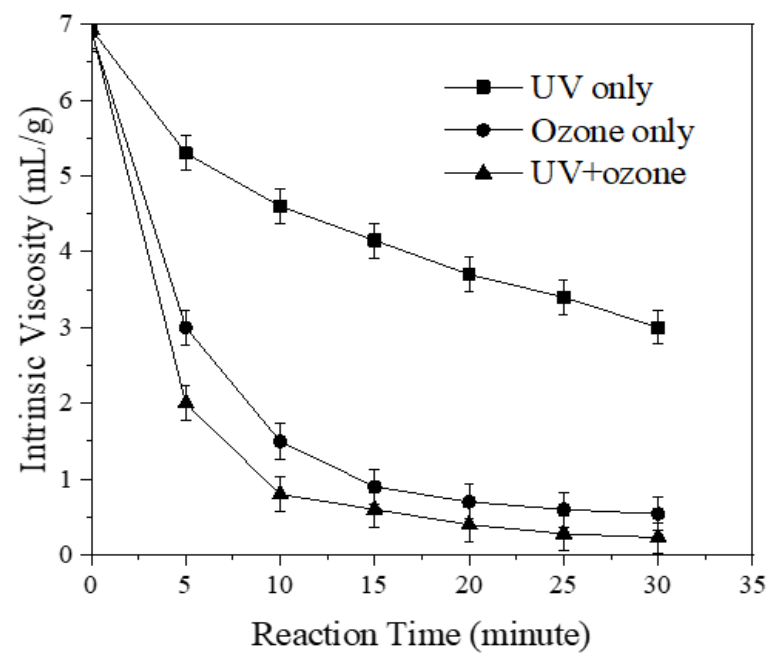

Figure 5. Effect of degradation of $\kappa$ carrageenan through $\mathrm{UV}, \mathrm{O}_{3}$ and $\mathrm{UV} / \mathrm{O}_{3}$ treatment.
$(\mathrm{OH} \bullet)$ in solution. These strong oxidizing species are capable of attacking the $\beta$-D- $(1,4)$ glycosidic linkages of $\kappa$-carrageenan [14,25], and the double bond scission is important for accelerating the process of depolymerization with $\mathrm{UV} / \mathrm{O}_{3}$.

Similarly, Prajapat and Gogate [16] reported on the higher efficiency demonstrated by using a combination of $\mathrm{UV} / \mathrm{O}_{3}$ for the degradation of guar gum, compared to the individual approach. Also, the ozone process caused a more effective decline in intrinsic viscosity than UV irradiation, with a degradation extent of $77.94 \%$ and $99.1 \%$, respectively. Yue at al. [17] reported the ozonation process as more efficient than ultraviolet irradiation in reducing the molecular weight of chitosan, based on the respective viscosity of $42.94 \%$ and $19.30 \%$ observed when used alone. Guirguis et al. [18] studied the treatment of chitosan with a combination of $\mathrm{UV} / \mathrm{O}_{3}$ and highlighted the possibility of bacteria activity promotion in the pharmaceutical field. Wang et al. [19] reported the performance comparison and degradation pathways of clofibric acid, using $\mathrm{UV}, \mathrm{O}_{3}$ and the combination of $\mathrm{UV} / \mathrm{O}_{3}$.

Studies have shown the capacity for ultraviolet radiation to substantially enhance ozone radiolysis [16-17], and photochemistry was identified to have an important influence on the production of polymers with low molecular weight. The double bond cleavage in the $\kappa$-carrageenan molecule is lower using the UV process than the $\mathrm{O}_{3}$ treatment. However, the $\mathrm{UV} / \mathrm{O}_{3}$ combination possesses an additional mechanism, characterized by the double bond scission, through a direct oxidation reaction, where $\mathrm{O}_{3}$ plays an important role in the degradation process. These phenomena demonstrate the potential for ozone photolysis to produce hydrogen peroxide, based on the initiation of free radical reaction mechanisms, which lead to the formation of hydroxyl radical. Moreover, combination of the $\mathrm{UV} / \mathrm{O}_{3}$ process primarily involved the rapid production of $\mathrm{OH} \bullet$ through UV ozone photolysis (Equation (6)-(10)) [31-32].

$$
\begin{aligned}
& \mathrm{O}_{3}+\mathrm{OH}^{-} \rightleftharpoons \mathrm{HO}_{2} \cdot+\mathrm{O}_{2}^{-} \bullet \\
& \mathrm{O}_{3}+\mathrm{HO}_{2}^{-} \stackrel{h v}{\rightleftharpoons} \mathrm{OH} \cdot+\mathrm{O}_{2}^{-} \cdot+\mathrm{O}_{2} \\
& \mathrm{O}_{3}+\mathrm{H}_{2} \mathrm{O} \stackrel{h v}{\longrightarrow} \mathrm{O}_{2}+\mathrm{H}_{2} \mathrm{O}_{2} \\
& \mathrm{O}_{3}+\mathrm{H}_{2} \mathrm{O} \stackrel{h v}{\longrightarrow} 2 \mathrm{OH} \cdot \\
& 2 \mathrm{O}_{3}+\mathrm{H}_{2} \mathrm{O}_{2} \rightleftharpoons 2 \mathrm{OH} \cdot+3 \mathrm{O}_{2}
\end{aligned}
$$


The $\mathrm{UV} / \mathrm{O}_{3}$ combination system is a complete oxidation system, which involves advanced processes, as the reactions probably ensue from the initiating species present in the water (Equation (6)), the free radicals formed from the photolysis of hydrogen peroxide (Equation (7)-(9)), and also from the reaction of ozone and hydrogen peroxide (Equation (10)). During the $\mathrm{UV} / \mathrm{O}_{3}$ process, the photon energies are calculated from Planck's constant $(h)$ and the radiation frequency $(v)$. This treatment involves the following possible types of direct oxidation/photolysis: ozonation, oxidation with hydrogen peroxide, and photolysis. Direct photolysis can be a significant kind of oxidation, so this type is first studied from the kinetics point of view.

\subsection{Kinetics}

During the oxidation process of polysaccharide depolymerization, all bonds of a polymer chain are equally susceptible to breakage, at a rate that is proportional to the remaining unbroken bonds. Therefore, the random depolymerization of a single-stranded polymer occurs according to Equation (11) [33]:

$$
\frac{1}{D P_{n, t}}=\frac{1}{D P_{n, 0}}+k t
$$

where $k$ is the rate constant for the bond cleavage of $\kappa$-carrageenan, while $D P_{n, t}$ and $D P_{n, 0}$ depict the average degrees of polymerization, at times $t$ and 0 , respectively. For this linear single-stranded sample polymer, the viscosity average molecular weight $(M)$ is linked with intrinsic viscosity, [ $\eta]$, through the Mark-Houwink equation, as shown in Equation (12) and (13) [8].

$$
\begin{aligned}
& {[\eta]=k_{M H} M^{\alpha}} \\
& M=\left(\frac{[\eta]}{k_{M H}}\right)^{1 / \alpha}
\end{aligned}
$$

where $k_{M H}$ and $\alpha$ are Mark-Houwink constants, and then the values of $k_{M H}$ and $\alpha$ in this research were 0.00598 and 0.90 , respectively. Furthermore, $M$ and [ $\eta$ ] are expressed in terms of $\mathrm{g} / \mathrm{gmol}$ and $\mathrm{mL} / \mathrm{g}$, respectively, and the rate constant $(k)$ of depolymerization is subsequently obtained from the plot of average molecular weight against time (Equation (14)).

$$
\frac{1}{M_{t}}-\frac{1}{M_{0}}=\left(\frac{k}{m}\right) t
$$

Combination of Equation (13) and Equation (14) leads to Equation (15).

$$
\begin{aligned}
& \frac{1}{[\eta]_{t}^{1 / \alpha}}-\frac{1}{[\eta]_{0}^{1 / \alpha}}=k^{\prime} t \\
& k^{\prime}=\frac{k_{o b s}}{m \times k_{M H}^{1 / \alpha}}
\end{aligned}
$$

The $k$ 'value can be obtained from plotting Equation (15) and extrapolating the slope. Therefore, it is possible to determine the observed kinetic rate constant $\left(k_{o b s}\right)$ from the $k$ ' value, using Equation (16), and the results obtained from different treatments are provided in Table 1. In addition, the percentage average absolute deviation (\%AAD) of the experiment and model was also calculated.

The ozone treatment was assessed to be more efficient than UV irradiation, as Table 1 shows the individual kinetic rate constant of ozone to be $7.877 \times 10^{-5} \mathrm{~min}^{-1}$ at a dosage of 125 $\mathrm{mg} / \mathrm{L}$. However, a previous study by Prasetyaningrum et al. [35] demonstrated value of $7.21 \times 10^{-5} \mathrm{~min}^{-1}$ at $\mathrm{pH} 10$ and a temperature of $30{ }^{\circ} \mathrm{C}$. Interestingly, a combination of $\mathrm{UV} / \mathrm{O}_{3}$ has been affiliated with an increase in the kinetic rate constant value, which was reported as $1.924 \times 10^{-4} \mathrm{~min}^{-1}$, using a treatment with $125 \mathrm{mg} / \mathrm{L}$ ozone and a UV lamp intensity

\begin{tabular}{|c|c|c|c|c|}
\hline \multicolumn{2}{|c|}{ Treatment } & \multirow[b]{2}{*}{$\begin{array}{c}\text { Experiment } k_{o b s} \\
\left(\min ^{-1}\right)\end{array}$} & \multirow[b]{2}{*}{$\begin{array}{l}\text { Calculated } k_{o b s} \\
\quad\left(\min ^{-1}\right)\end{array}$} & \multirow[b]{2}{*}{$\mathrm{AAD}(\%)$} \\
\hline $\begin{array}{c}\text { Ozone dosage } \\
(\mathrm{mg} / \mathrm{L})\end{array}$ & $\begin{array}{l}\text { UV intensity } \\
\left(\mathrm{mW} / \mathrm{cm}^{2}\right)\end{array}$ & & & \\
\hline 45 & - & $3.118 \times 10^{-5}$ & $3.533 \times 10^{-5}$ & 13.31 \\
\hline 80 & - & $5.106 \times 10^{-5}$ & $5.281 \times 10^{-5}$ & 3.43 \\
\hline 125 & - & $7.877 \times 10^{-5}$ & $7.214 \times 10^{-5}$ & 8.42 \\
\hline- & 13.33 & $4.876 \times 10^{-6}$ & $5.083 \times 10^{-6}$ & 4.26 \\
\hline- & 26.67 & $5.902 \times 10^{-6}$ & $6.166 \times 10^{-6}$ & 4.49 \\
\hline- & 40.00 & $7.313 \times 10^{-6}$ & $6.904 \times 10^{-6}$ & 5.59 \\
\hline 125 & 40.00 & $1.924 \times 10^{-4}$ & $2.017 \times 10^{-4}$ & 4.79 \\
\hline
\end{tabular}
of $40.00 \mathrm{~mW} / \mathrm{cm}^{2}$.

The degradation kinetics of organic compounds using this combination has previously been conducted. Prajapat et al. [16] eval-

Table 1. The observed kinetics-rate constants $k_{o b s}$ for different AOPs methods. 
uated the synergetic effect of ozone, ultraviolet, and ultrasound on the kinetic rate constant of guar gum degradation. Meanwhile, this current study showed a value of $2.28 \times 10^{-1} \mathrm{~min}^{-1}$, using an ozone concentration of $100 \mathrm{mg} / \mathrm{L}$, after a reaction time of 30 minutes. Benitez et al. [36] reported on the increased propensity for this combination to improve the kinetics rate constant of carbofuran degradation, based on the record of $2.28 \times 10^{-5} \mathrm{~s}^{-1}$, reported at $\mathrm{pH} 9$ and a temperature of $20^{\circ} \mathrm{C}$. This outcome was three times higher than the result obtained from the individual use of conventional ozonation under similar experimental conditions.

Therefore, the kinetic rate constants obtained in this research are confirmed to be different from previous studies, due to variations in reaction conditions. This evaluation parameter is assumed to be dependent on the ozone dosage and UV irradiation intensity (Table 1), hence increasing both factors elevates the $k_{o b s}$ value, suggestive of a correlation. This strongly insinuates the kinetic rate constant of $\kappa$ carrageenan depolymerization as a function of ozone dosage and UV irradiation intensity.

It is possible to rewrite this statement as a mathematical correlation as provided in Equation (17), characterized by an exponential dependence. Therefore, Equation (18) is revealed as the suggested equation of kinetic rate constant, which is subsequently linearized as seen in Equation (19).

$k_{o b s}=f\left(C_{O_{3}}, I_{U V}\right)$

$k_{o b s}=\varepsilon C_{O_{3}}^{a} I_{U V}^{b}$

$\ln k_{\text {obs }}=\ln \varepsilon+a \ln C_{O_{3}}+b \ln I_{U V}$

where $\varepsilon, a$ and $b$ are constants determined through the derivation with multiple regression analysis (MRA). This is a statistical method used to correlate the behavior of independent variables (ozone dosage and UV irradiation intensity), considering possible variations, in order to ascertain the individual and combined impact on the dependent variable $\left(k_{o b s}\right)$.

The multiple regression method provides a short step to simultaneously determine the constants $a, b$ and $\varepsilon$. This evaluation was performed with Equation (19), using all available data. In addition, Statistica 6.0 software was used for the statistical analysis and evaluation of results. Table 2 demonstrates the outcome of regression analysis, where the $p$-value for each coefficient is observed to be lower than 0.05 , hence the coefficients obtained are significant.

Table 3 shows the result of statistical analysis, indicating the closeness of the regression coefficient $\left(R^{2}\right)$ and the adjusted $R^{2}$ to 1 . Therefore, the model coefficient obtained is significant for the prediction of $k_{o b s}$. Based on the ANOVA (Table 3), the $F$-Fisher theoretical value and the $\alpha$-significance level were confirmed to be significant, while the $F_{\text {theoretical }}$ is calculated with probability $\alpha=5 \%$ and (two, six)degree of freedom $\left[\mathrm{F}_{0.05}(2,6)\right]$ from the $F$-table, and 19.330 was obtained. This study outcome is confirmed from the fact that the observed $F$ is higher than $F_{\text {theoretical }}$.

Therefore, the multiple regression equation of $k_{o b s}$ is provided in Equation (20).

$\ln k_{a b s}=-12.9114+0.6989 \ln C_{o_{3}}+0.2787 \ln I_{U V}$

Equation (20) shows the value of $a$ as 0.6989 , and $b$ as 0.2787 , while $\varepsilon\left(2.4696 \times 10^{-6}\right)$ was calculated from the natural exponential of the intercept. Hence, it is possible to rewrite Equation (18) as Equation (21).

Table 2. Summary of regression result.

\begin{tabular}{lccc}
\hline & Coefficients & Standard error & $p$-value \\
\hline Intercept & -12.9114 & 0.0881 & $6.8018 \times 10^{-12}$ \\
$\ln C_{O 3}$ & 0.6989 & 0.0179 & $1.9194 \times 10^{-8}$ \\
$\ln I_{U V}$ & 0.2787 & 0.0238 & $2.3507 \times 10^{-5}$ \\
\hline
\end{tabular}

Table 3. Summary of analysis of variance (ANOVA).

\begin{tabular}{lccccc}
\hline & Df & SS & MS & F & Significance F \\
\hline Regression & 2 & 15.0845 & 7.5423 & 1012.4382 & $2.5800 \times 10^{-8}$ \\
Residual & 6 & 0.0446 & 0.0074 & & \\
Total & 8 & 15.1292 & & & \\
\hline Multiple R & 0.9985 & & & & \\
$\mathrm{R}^{2}$ & 0.9970 & & & & \\
Adjusted R & & & & & \\
\hline
\end{tabular}




$$
k_{o b s}=\left(2.4696 \times 10^{-6}\right) C_{O_{3}}^{0.6989} I_{U V}^{0.2787}
$$

Equation (21) is used to calculate the $k_{o b s}$ from the data provided, and the result is provided in Table 1. Therefore, the suggested equation of kinetic rate constant is concluded to be merely suitable for predicting the $k_{o b s}$ value of $\kappa$-carrageenan depolymerization.

The $k_{\text {obs }}$ values calculated using Equation (21) are used to estimate the predicted intrinsic viscosity for combined ( $\left.\mathrm{UV} / \mathrm{O}_{3}\right)$ treatment, using the equation derived from Equation (15), as shown in Figure 6. This parameter is assumed to be excellently predicted, hence the suggested $k_{\text {obs }}$ equation is acceptable for the prediction of the kinetic rate constant in $\kappa$-carrageenan depolymerization, using ozone and UV irradiation.

Table 1 shows the generation of higher $k_{o b s}$ values after ozone treatment, compared to UV irradiation. This result suggests that ozone treatment has a relatively more significant effect on $\kappa$-carrageenan degradation, and a good agreement is demonstrated in Equation (21). Also, the exponent constant value was a higher for ozone dosage than UV intensity. Several prior investigations have also reported similar findings. Prajapat and Gogate [16] affiliated the ozone treatment with higher guar gum effect, compared to the UV irradiation. Yue et al. [37] also reported a similar impact on the degradation of chitosan, and this phenomenon is explained by the essential photochemical effect occurring within the polymers. This entails the cleavage of side groups, resulting in the formation of volatile products. Furthermore, the generation of hydroxyl radicals is relatively lower using UV treatment and the rate of polymer degradation is also reduced [16].

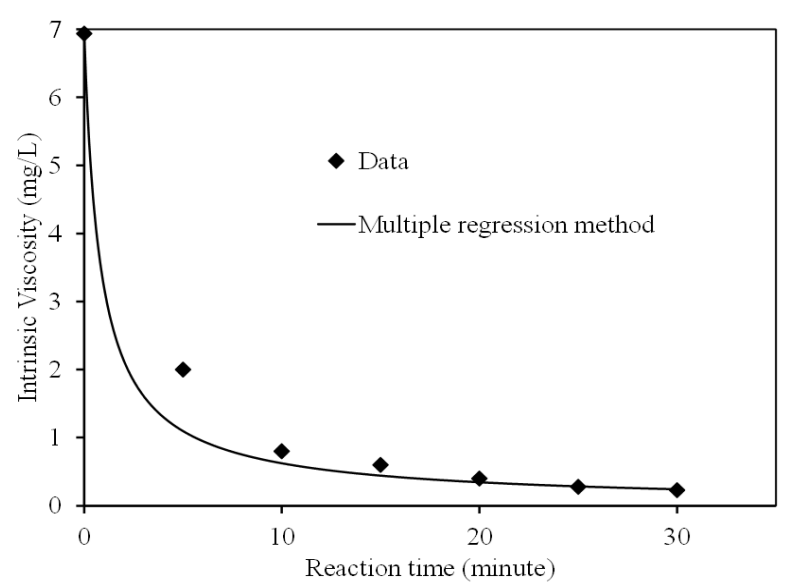

Figure 6. Intrinsic viscosity profile of data and the calculated combined reaction treatment.

\subsection{Products Characterization}

\subsubsection{FT-IR analysis}

FT-IR spectroscopy has been adopted in the study of polysaccharide physicochemical properties, and the observed absorption bands confirm the chemical structure of $\kappa$-carrageenan reported by Tajo et al. [34]. The results indicate the presence of very strong bands in the 1230$1270 \mathrm{~cm}^{-1}$ ( $\mathrm{S}=\mathrm{O}$ of sulfate esters) and 1010$1080 \mathrm{~cm}^{-1}$ (glycosidic linkage) regions. Meanwhile, those observed at $933-928 \mathrm{~cm}^{-1}$ are associated with the 3,6-anhydrous bridge coupling of $\mathrm{C}-\mathrm{O}$ stretching vibrations, and the presence of a clear band at $840-850 \mathrm{~cm}^{-1}$ determines the exact positions of sulfates. Conversely, the FTIR spectra of native and treated $\kappa$ carrageenan using UV irradiation, ozonation, and combination of $\mathrm{UV} / \mathrm{O}_{3}$ are shown in Figure 7.

These results show the absence of a change in the functional properties of $\kappa$-carrageenan during the degradation treatment with $\mathrm{UV} / \mathrm{O}_{3}$ combination. In addition, the sulfate content was observed to be relatively stable during the oxidation process at wavenumbers 1245,928 and $840 \mathrm{~cm}^{-1}$, although there was a decline in peak intensity at $1010-1080 \mathrm{~cm}^{-1}$. This proves the occurrence of glycosidic linkage scission in $\kappa$-carrageenan during the degradation process, and no new band assigned to the carboxylic group was observed near the $1735 \mathrm{~cm}^{-1}$, hence the results confirmed the presence of polysaccharides degradation mainly based on $\beta$-glycosidic linkage cleavage, and no carboxylic groups was formed [37]. Furthermore, the FTIR results clearly establish the absence of any significant changes in the functional groups

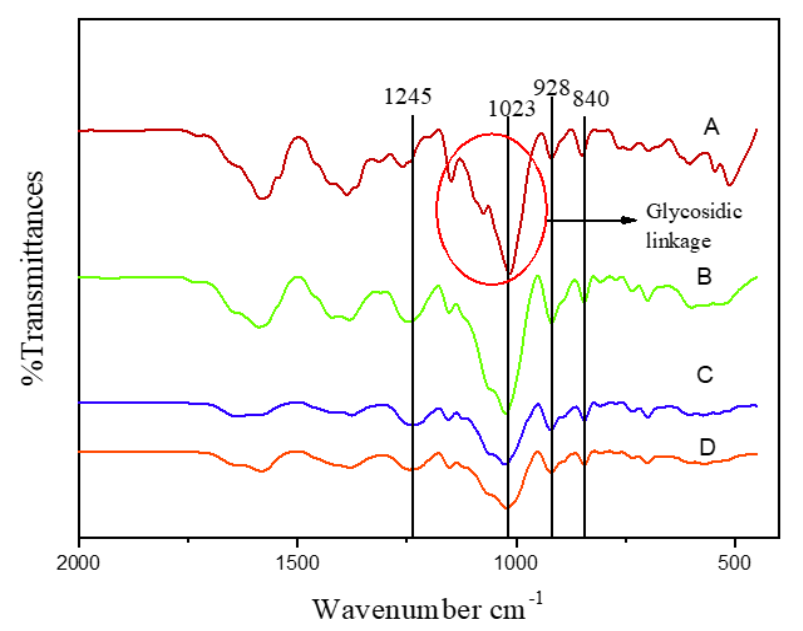

Figure 7. FT-IR analysis A)Native; B) UV irradiation; C) Ozonation process; D) Combination of $\mathrm{UV} / \mathrm{O}_{3}$. 
and chemical structure during the treatment. This phenomenon occurs because the free radical-induced chain scission was only capable of breaking the polymer structure by reducing the viscosity, without causing any changes to the functional properties.

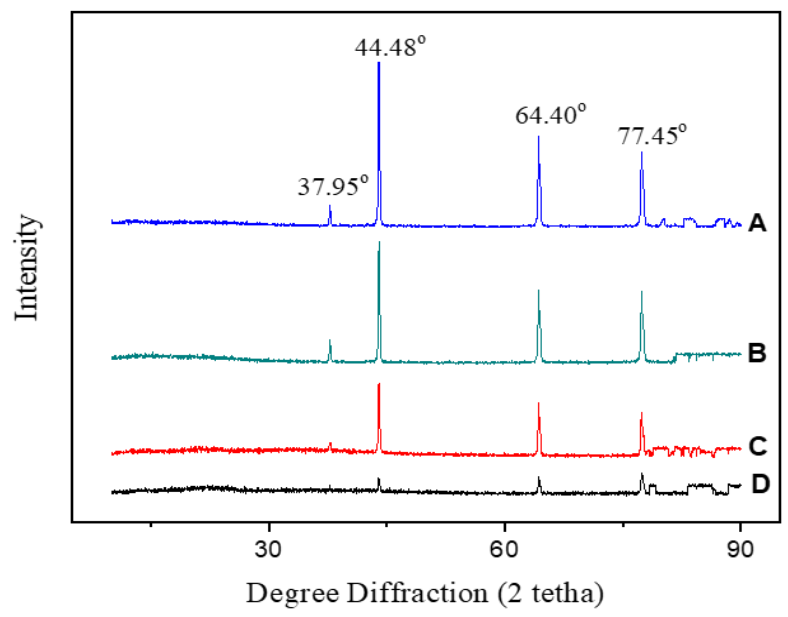

Figure 8. X-ray Diffraction analysis: A) Native; B) UV irradiation; C) Ozonation process; D) Combination of $\mathrm{UV} / \mathrm{O}_{3}$.
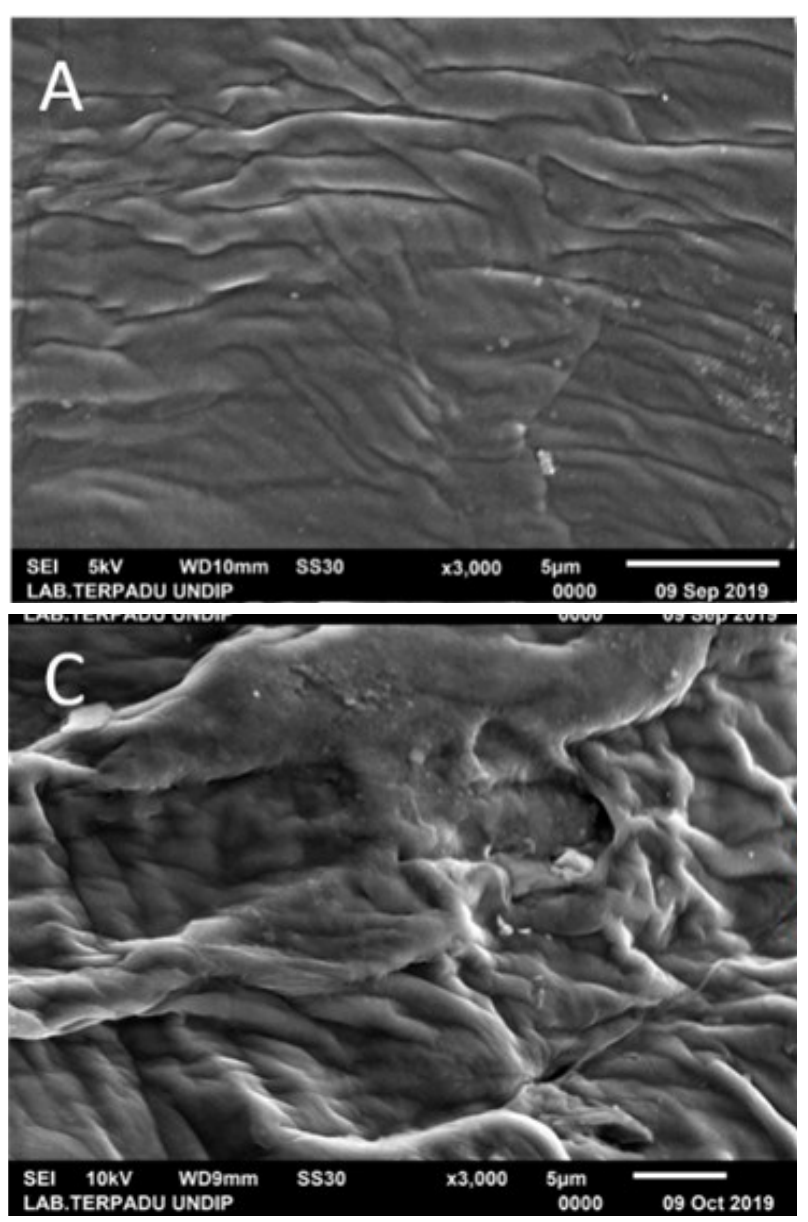

\subsubsection{X-ray Diffraction analysis}

The XRD pattern of the native and treated $\kappa$-carrageenan using $\mathrm{UV}, \mathrm{O}_{3}$, and the combination of $\mathrm{UV} / \mathrm{O}_{3}$ are presented in Figure 8 , and characteristic peaks at $2 \theta=37.95^{\circ}$, $44.48^{\circ}, 64.40^{\circ}$, and $77.45^{\circ}$, were observed with the native variety. The XRD analysis result showed a decline in the main peak for the treated $\kappa$-carrageenan, compared to the native form. This indicates the tendency of amorphous formation and low cristallinity potentials. Li et al. [38] previously reported on the ease of degrading chitosan in the amorphous regions into compounds with lower molecular weight. Similarly, Prasetsung et al. [39] described the characteristic of chitosan decomposed by plasma based on the content of lower main peak intensity, compared to the native form.

\subsubsection{SEM analysis}

The surface morphology of the solid samples was analyzed using Emission Scanning Electron Microscope (SEM). Figure 9 shows the SEM analysis of native and treated $\kappa$ -
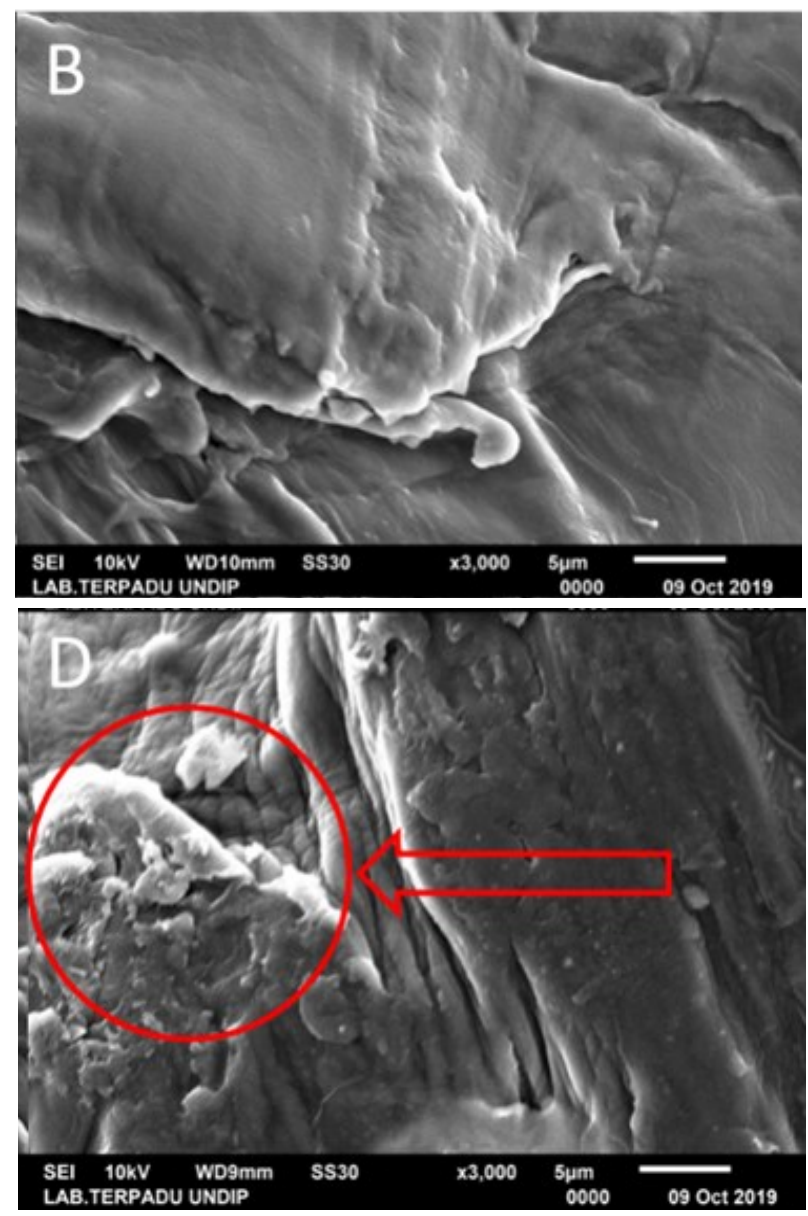

Figure 9. SEM analysis of A) Native; B) UV irradiation; C) Ozonation process; D) Combination of $\mathrm{UV} / \mathrm{O}_{3}$. 
carrageenan, using UV irradiation, ozonation, and combination of $\mathrm{UV} / \mathrm{O}_{3}$ (magnification of 3000x). Therefore, a correlation was established with the results of XRD analysis, based on the depolymerized sample. The treatment with $\mathrm{UV} / \mathrm{O}_{3}$ combination demonstrated shapes that were relatively irregular, more amorphous and rough, compared to the native form (Figure 9 (D)). There was also a change in the morphological characteristics after the process of depolymerization, which result from glycosidic linkage cleavage. Conversely, the research conducted by Fojas et al. [40] and Shahbazi et al. [41] demonstrated a similar trend.

\section{Conclusions}

This research established the effectiveness of different approaches, including UV irradiation, ozonation, and a combination of $\mathrm{UV} / \mathrm{O}_{3}$, which efficiently depolymerized the sample, in the degradation of $\kappa$-carrageenan. Furthermore, the extent of activity for all three treatment methods was $53.86 \%, 91.59 \%$, and $96.68 \%$, respectively. The kinetic rate of depolymerization using $\mathrm{UV} / \mathrm{O}_{3}$ was more rapid than individual approaches, resulting from the production of hydrogen radicals, which is capable of breaking the linkages in $\kappa$-carrageenan. The values of $k_{o b s}$ were higher with the ozone treatment reactions than the UV irradiation, suggesting that $\mathrm{O}_{3}$ confers a more significant effect. Hence, the kinetic model of the depolymerization equation using the combination treatment is $k_{o b s}=\left(2.4696 \times 10^{-6}\right)$ $\mathrm{C}_{\mathrm{O}^{3}}{ }^{0.6989} \mathrm{IUV}_{U V^{0.2787}}$. Conversely, there are no significant changes in the sulfate content as observed in all treatments. The FT-IR analysis of native and degraded $\kappa$-carrageenan demonstrated the absence of any significant changes in functional properties, while XRD showed a relative decline in the main peak for the treated variety. Finally, the morphological properties of the sample degraded with the combination of $\mathrm{UV} / \mathrm{O}_{3}$ were amorphous and rough.

\section{Acknowledgments}

This research was funded through the Penelitian Dasar Unggulan Perguruan Tinggi (PDUPT) Research Grant Kemenristek DIKTI of Indonesia, 2020. The authors are grateful to the technical assistance provided by Ms. Dwi Purwati during the laboratory analysis of samples.

\section{References}

[1] Van de Velde, F., Lourenco, N.D., Pinheiro, H.M., Bakker, M. (2002). Carrageenan : A Food-Grade and Biocompatible Support for Immobilisation Techniques. Advanced Synthesis and Catalyst, 344(8), 815-835. DOI: 10.1002/1615-4169(200209)344:8<815::AIDADSC815>3.0.CO;2-H

[2] Liu, S., Chan, W.L., Li, L. (2015). Rheological Properties and Scaling Laws of k-Carrageenan in Aqueous Solution. Macromolecules, 48(20), 7649-7657. DOI: 10.1021/acs.macromol.5b01922.

[3] Yuan, H., Song, J. (2011). Preparation, Structural Characterization and in Vitro Antitumor Activity of kappa-Carrageenan Oligosaccharide Fraction from kappaphycus striatum. Journal of Applied Phycology, 17(1), 7-13. DOI: 10.1007/s10811-005-5513-8.

[4] Sun, Y., Yang, B., Wu, Y., Liu, Y., Gu, X., Zhang, H., Wang, C., Cao, H., Huang, L., Wang, Z. (2015). Structural Characterization and Antioxidant Activities of $\mathrm{k}$-Carrageenan Oligosaccharides Degraded by Different Methods. Food Chemistry, 178, 311-318. DOI: 10.1016/j.foodchem.2015.01.105.

[5] Wang, W., Zhang, P., Yua, G.L., Li, C.X., Hao, C., Qi, X., Zhang, L.J., Guan, H.S. (2012). Preparation and Anti-Influenza A Virus Activity of $\mathrm{k}$-Carrageenan Oligosaccharide and Its Sulphated Derivatives. Food Chemistry, 133(3), 880-888. DOI: 10.1016/j.foodchem.2012.01.108.

[6] Kalitnik, A.A., Barabanova, A.O.B., Nagorkaya, V.P., Reunov, A.V., Glazunov, V.P., Solov'eva, T.F., Yermak, I.M. (2013). Low Molecular Weight Derivatives of Different Carrageenan Types and their Antiviral Activity. Journal of Applied Phycology, 25(1), 65-72. DOI: 10.1007/s10811012-9839-8.

[7] Yermak, I.M., Barrabanova, A.O., Aminin, D.L., Davydova, V.N., Sokolova, E.V., Solo'eva, T.F., Kim, Y.H., Shin, K.S. (2012). Effect of Structural Peculiarities of Carrageenan on Their Immunomodulatory and Anticoagulant Activities. Carbohydrate Polymers, 87, $713-720$. DOI: 10.1016/j.carbpol.2011.08.053 .

[8] Lai, V.M.F., Lii, C.Y., Hung, W.L., Lu, T.J. (2000). Kinetic Compensation Effect in Depolymerization of Food Polysaccharides. Food Chemistry, 68(3), 319-325. DOI: 10.1016/S0308-8146(99)00198-3.

[9] Wu, S.J. (2012). Degradation of KCarrageenan by Hydrolysis with Commercial a-Amylase. Carbohydrate Polymers, 89, 394396. DOI: 10.1016/j.carbpol.2012.03.019. 
[10] Duan, F., Yu, Y., Liu, Z., Tian, L., Mou, H. (2016). An Effective Method for the Preparation of Carrageenan Oligosaccharides Directly from Eucheuma cottonii using Cellulase and Recombinant $\mathrm{x}$-Carrageenase. Algal Research, 15, 93-99. DOI: 10.1016/j.algal.2016.02.006.

[11] Zhou, G., Yao, W., Wang, C. (2006). Kinetics of Microwave Degradation of $\lambda$-Carrageenan from Chondrus Ocellatus. Carbohydrate Polymers, 64, $73-77$. D O I : 10.1016/j.carbpol.2005.10.023.

[12] Ratnawati, R., Prasetyaningrum, A., Wardhani, D.H. (2016). Kinetics and Thermodynamics of Ultrasound-Assisted Depolymerization of $\mathrm{k}$-Carrageenan. Bulletin of Chemical Reaction Engineering \& Catalysis, $11, \quad 48-58$. D O I : 10.9767/bcrec.11.1.415.48-58.

[13] Taghizadeh, M.T., Abdollahi, R. (2015). Influence of Different Degradation Techniques on the Molecular Weight Distribution of $\mathrm{k}$ - Carrageenan. International Journal of Biochemistry and Biophysics, 3, 25-33. DOI: 10.13189/ijbb.2015.030301.

[14] Abad, L.V., Kudo, H., Saiki, S., Nagasawa, N., Tamada, M., Fub, H., Muroya, Y., Lin, M., Katsumura, Y., Relleve, L.S., Aranilla, C.T., DeLaRosa, A.M. (2010). Radiolysis Studies of Aqueo k-Carrageenan. Nuclear Instruments and Methods in Physics Research Section B, $268(10), \quad 1607-1612$. D O I : 10.1016/j.nimb.2010.02.006.

[15] Zu'ñiga, E.A., Matsuhiro, Betty., Mejı'as, E. (2006). Preparation of A Low-Molecular Weight Fraction by Free Radical Depolymerization of The Sulfated Galactan from Schizymenia Binderi (Gigartinales, Rhodophyta) and Its Anticoagulant Activity. Carbohydrate Polymers, 66, 208-215. DOI : 10.1016/j.carbpol.2006.03.007.

[16] Prajapat, A.L., Gogate, P.R. (2015). Intensification of Degradation of Guar Gum: Comparison of Approaches Based on Ozone, Ultraviolet and Ultrasonic Irradiations. Chemical Engineering And Process, 98, 165173. DOI: 10.1016/j.cep.2015.09.018.

[17] Yue, W., Yao, P., Wei, Y., Mo, H. (2008). Synergetic Effect of Ozone and Ultrasounic Radiation on Degradation of Chitosan. Polymer Degradation and Stability, 93, 1814$\begin{array}{llllllll}1 & 8 & 2 & 1 & . & \text { D } & \text { O } & \text { I }\end{array}$ 10.1016/j.polymdegradstab.2008.07.010.

[18] Guirguis, O.W., El-Bassyouni, G.T., Esawy, M.A., Abd Elkader, N.R., Mahmoud, H.M., Mostafa, H.M., Abdel-Zaher, N.A. (2016). Exposure of Chitosan to UV/ozone: Structural Information and Antibacterial Activity.
Journal of Applied Pharmaceutical Science, $6\left(\begin{array}{lll}1 & 2\end{array}\right), \quad 124-130$. D O I : 10.7324/JAPS.2016.601217.

[19] Wang, Y., Li, H., Yi, P., Zhang, H. (2019). Degradation of Clofibric Acid by UV, O3 and UV/O3 Process: Performance Comparison and Degradation Pathways. Journal of Hazardous Materials, 379, 001-011. DOI: 10.1016/j.jhazmat.2019.120771.

[20] Chen, Z., Fang, J., Chihhao, F., Shang, C. (2016). Oxidative Degradation of Nnitrosopyrrolidine by The Ozone/UV Process: Kinetics and Pathways. Chemosphere, 150, $\begin{array}{llllllllllll}7 & 3 & 1 & - & 7 & 3 & 9 & & \text { D } & \mathrm{O} & \mathrm{I} & \text { : }\end{array}$ 10.1016/j.chemosphere.2015.12.046.

[21] Dai, Q., Chen, L., Chen, W., Chen, J. (2015). Degradation and Kinetics of Phenoxyacetic Acid in Aqueous Solution by Ozonation. Separation and Purification Technology, 142, 287-292. DOI: 10.1016/j.seppur.2014.12.045.

[22] Pawar, I.A., Joshi, P.J., Kadam, A.D., Pande, N.B., Kamble, P.H., Hinge, S.P., Benerjee, B.S., Mohod, A.V., Gogate, P.R.. (2014). Ultrasound-based Treatment Approaches for Intrinsic Viscosity Reduction of Polyvinyl Pyrrolidone (PVP). Ultrasonic Sonochemical, $21, \quad 1108-1116 . \quad$ D O I : 10.1016/j.ultsonch.2013.12.013.

[23] Marimuthu, A., Madras, G. (2008). Photocatalytic Oxidative Degradation of Poly (alkyl acrylates) with $\mathrm{NanoTiO}_{2}$. Industrial and Engineering Chemistry Research, 47, 2182-2190. DOI: 10.1021/ie0712939.

[24] Hamad, D., Mehrvar, M., Dhib, R. (2014). Experimental Study of Polyvinyl Alcohol Degradation in Aqueous Solution by $\mathrm{UV} / \mathrm{H}_{2} \mathrm{O}_{2}$ Process. Polymer Degradation and Stability, $\begin{array}{llllllll}1 & 0 & 3 & 7 & 5 & - & 8 & 2\end{array}$ D O I : 10.1016/j.polymdegradstab.2014.02.018.

[25] Prasetyaningrum, A., Jos, B., Ratnawati, R. (2017). Effect of Ozonation Process on Physicochemical and Rheological Properties of k-Carrageenan. Scientific Study \& Research Chemistry \& Chemical Engineering, Biotechnology, Food Industry, 18(1), 009-018.

[26] Oh, B.S., Kim, K.S., Kang, M.G., Oh, J.H., Kang, J.W. (2005). Kinetic Study and Optimum control of the ozone/UV process measuring hydrogen peroxide formal in-situ. Ozone: Science and Engineering, 27, 421-430. DOI: $10.1080 / 01919510500349234$.

[27] Mzoughi, Z., Chakroun, I., Hamida, S.B., Rihouey, C., Mansour, H.B., Cerf, D.L., Majdoub, H. (2017). Ozone treatment of polysaccharides from Arthrocnemum indicum: Physico-chemical characterization and antiproliferative activity. Biological Macromolecules, 105, 1315-1323. DOI: 10.1016/j.ijbiomac.2017.07.151. 
[28] Tiwari, B.K., Muthukumarappan, K., O'Donnell, C.P., Chenchaiah, M., Cullen,P.J. (2008). Effect of Ozonation on The Rheological and Colour Characteristics of Hydrocolloid Dispersions. Food Research International, 41, $\begin{array}{llllllllllllll}1 & 0 & 3 & 5 & - & 1 & 0 & 4 & 3 & . & & \text { D } & \mathrm{O} & \mathrm{I}\end{array}$ : 10.1016/j.foodres.2008.07.011.

[29] Chan, H.T., Leh, C.P., Bhat, R., Senan, C., Williams, P.A., Karim, A.A. (2011). Molecular Structure, Rheological and Thermal Characteristics of Ozone-oxidized Starch. Food Chemistry, 126, 1019-1024. DOI: 10.1016/j.foodchem.2010.11.113.

[30] Cataldo, F. (2007). On The Action of Ozone on Gelatin. International Journal of Biological Macromolecules, 41(2), 210-216. DOI: 10.1016/j.ijbiomac.2007.02.008.

[31] Peyton, G.R., Glaze, W.H. (1988). Destruction of Pollutants in Water with Ozone in Combination with Ultraviolet Radiation. 3. Photolysis of Aqueous Ozone. Enviromental Science Technology, 22, 761-767. DOI: 10.1021/es00172a003.

[32] Rao, Y.F., Chu, W. (2009). A New Approach to Quantify the Degradation Kinetics of Linuron with UV, Ozonation and $\mathrm{UV} / \mathrm{O}_{3}$ Processes. Chemosphere, 74, 1444-1449. DOI: 10.1016/j.chemosphere.2008.12.012.

[33] Tanford, C. (1961). Phisical Chemistry of Macromolecules. Edition. New York: John Wiley and Sons, Inc.

[34] Tajo, E., Prado, J. (2003). Chemical Composition of Carrageenan Blends Determined by IR Spectroscopy Combined with a PLS Multivariate Calibration Method. Carbohydrate Research, 338, 1309-1312. DOI: 10.1016/S0008-6215(03)00144-7.

[35] Prasetyaningrum, A., Ratnawati, R., Jos, Bakti. (2017). Kinetics of Oxidation Depolymerization of k-carrageenan by Ozone. Bulletin of Chemical Reaction Engineering \& Catalysis, 12(2), 235-242. DOI: 10.9767/bcrec.12.2.805.235-242.
[36] Benitez, F.J., Beltran-Heredia, J., Gonzales, T. (1994). Degradation By Ozone and UV Radiation of The Herbicide Cyanazine. Ozone: Science and Engineering: The Journal of The International Ozone Associatio, 16 (3), 213234. DOI: $10.1080 / 01919519408552499$.

[37] Yue, W., He, R., Yao, P., Wei, Y. (2009). Ultraviolet Radiation-induced Accelerated Degradation of Chitosan by Ozone Treatment. Carbohydrate Polymers, 77(3), 639-642.

[38] Li, J., Cai, J., Fan, L. (2008). Effect of Sonolysis on Kinetics and Physicochemical Properties of Treated Chitosan. Journal of Applied Polymer Science, 109, 2417-2425. DOI: 10.1002/app.28339.

[39] Prasetsung, S. Damrongsakkul, N. Saito. (2013). Degradation of $\beta$-chitosan by Solution Plasma Process (SPP). Polymer Degradation and Stability, 98, 2089-2093. DOI: 10.1016/j.polymdegradstab.2013.07.001.

[40] Fojas, J.J.R., De Leon, R.L., Abad, L.V. (2013). Effect of Irradiation to Morphological. Physicochemical and Biocompatibility Properties of Carrageenan, International Journal Biotechnology and Bioengineering, 7(5), 320-323. DOI: 10.5281/zenodo.1073397.

[41] Shahbazi, M., Rajabzadeh, G., Ettelaie, R., and Rafe, A. (2016). Kinetic Study Of $R m$ kappa-Carrageenan Degradation And Its Impact On Mechanical And Structural Properties Of Chitosan/Rm kappaCarrageenan Film. Carbohydrate Polymers, 142, 167-176. DOI: 10.1016/j.carbpol.2016. 01.037 . 